\title{
Ensaio sobre as inter-relações entre arquitetura escolar, cibercultura e ensino de Ciências: desafios e propostas para as juventudes da Geração $Y$
}

\section{Essay on the interrelationships between school architecture, cyberculture and science teaching: challenges and proposals for Generation Y youth}
M. FERREIRA ${ }^{* 1}$,
O. L. S. FILHO ${ }^{1}$,
M. R. M. Costa ${ }^{1}$,
K. O. Portugal ${ }^{1}$,
L. M. LIMA ${ }^{1}$,
G. P. SOUZA ${ }^{1}$,
J. V. S. ROCHA ${ }^{1}$,
P. L. Alves ${ }^{1}$,
H. M.
ZANETTI $^{1}$,
H. C. S. SACERDote ${ }^{1}$
${ }^{1}$ Universidade de Brasília.

\begin{abstract}
Resumo
Há uma diversidade de recursos tecnológicos que podem contribuir para as inovações metodológicas no ensino de Ciências, mas é interessante observar o quanto é difícil a adoção de novas ideias. Tal dificuldade está presente nos processos de difusão e incorporação de inovações, mesmo que elas apresentem vantagens em relação à ideia vigente. Neste estudo, deseja-se estabelecer um confronto com o que é considerado tradicional no ensino de Ciências. Para tanto, o objetivo é investigar como a organização e a arquitetura do ambiente escolar podem favorecer a atenção e a concentração dos alunos, em uma perspectiva crítica e significativa. O arcabouço teórico deste ensaio é interdisciplinar, baseando-se nos estudos de Foucault (1999a; 1999b; 1999c), Lévy (1993), Vygotski (1988), Kaplan (1995), dentre outros. A metodologia adotada ancora-se em um estudo bibliográfico de caráter exploratório. Metodologicamente, o ensaio foi dividido em quatro partes: na primeira, discute-se a inteligência coletiva (LÉVY, 1993) e a zona de desenvolvimento proximal (VYGOTSKI, 1988); na segunda, aborda-se a articulação entre ensino de Ciências e tecnologias digitais; na terceira, trata-se da arquitetura no processo de aprendizagem; e, na quarta, lançam-se duas propostas de ambientes de aprendizagem: a sala de aula articulada e o espaço de colaboração. Como ensaio, as contribuições deste estudo estão voltadas para a exploração e a discussão de temas recentes (ADORNO, 1994), trazendo, como mote, estudos que possam lançar contribuições teóricas possíveis de ulterior aplicação.
\end{abstract}

Palavras-chave: Arquitetura. Cibercultura. Ciências. Ensino.

*marcellof@unb.br 


\begin{abstract}
There is a diversity of technological resources that can contribute to methodological innovations in science education, but it is interesting to note how difficult it is to adopt new ideas. Such difficulty is present in the processes of diffusion and incorporation of innovations, even if they present advantages in relation to the current idea. In this study, it is desired to establish a confrontation with what is considered traditional in science education. Therefore, the objective is to investigate how the organization and architecture of the school environment can favor students' attention and concentration, in a critical and meaningful perspective. The theoretical framework of this essay is interdisciplinary, based on the studies of Foucault (1999a; 1999b; 1999c), Lévy (1993), Vygotski (1988), Kaplan (1995), among others. The methodology adopted is based on an exploratory bibliographic study. Methodologically, the essay was divided into four parts: in the first, collective intelligence (LÉVY, 1993) and the zone of proximal development (VYGOTSKI, 1988) are discussed; in the second, the articulation between science teaching and digital technologies is addressed; in the third, it is about architecture in the learning process; and in the fourth, two proposals for learning environments are launched: the articulated classroom and the collaboration space. As an essay, the contributions of this study are focused on the exploration and discussion of recent themes (ADORNO, 1994), bringing, emphatically, studies that can launch possible theoretical contributions for further application.
\end{abstract}

Keywords: Architecture. Cyberculture. Sciences. Teaching.

\title{
I. INTRODUÇ̃̃̃O
}

Palfrey e Gasser (2008) explicam que a chamada Geração Y - também conhecida como geração da internet e milênicos (tradução da expressão em inglês Millennials) - é constituída por aqueles que nasceram a partir de 1974. Rocha-de-Oliveira, Piccinini e Bitencourt (2012, p. 554) destacam que "ao analisar o conceito de Geração Y sobre as bases da sociologia da juventude, vemos que a discussão atual tem definida uma única juventude na contemporaneidade, quando, na verdade, o conceito de juventude é múltiplo: as juventudes". Isso decorre do fato de que "cada grupo juvenil será influenciado pela região e local (rural ou urbano) em que habita, nível de instrução, curso de formação, vinculação a instituições etc. Ou seja, um único conceito não consegue congregar todo o mosaico de vivências juvenis [...]" (ROCHA-DE-OLIVEIRA; PICCININI; BITENCOURT, 2012, p. 554).

Diante desse panorama, questiona-se como construir o processo de ensino e aprendizagem para essas juventudes que, ao mesmo tempo que não se deixam subsumir pelo conceito homogeneizador de classe social, também se distinguem de outras gerações que, por exemplo, não tinham à disposição recursos tecnológicos digitais, tais como computadores, tablets, smartphones, dentre outros.

De acordo com Xavier (2011), ao pesquisar o letramento digital da Geração Y em um estudo de caso no território nacional ${ }^{1}$, o conceito de aprendizagem pode ser entendido como:

\footnotetext{
${ }^{1} \mathrm{O}$ estudo foi realizado, durante oito meses, em uma unidade escolar com um grupo de 25 alunos, entre 9 a 14 anos, matriculados entre a $3^{\mathrm{a}}$ e a $7^{\mathrm{a}}$ série do Ensino Fundamental - atualmente $4^{\circ}$ e $8^{\circ}$ ano do Ensino Fundamental, respectivamente.
} 
O processo de aprendizagem tem a ver com mudança cognitiva, ou seja, significa transformação mental dentro daquele que aprende. Isto acontecerá se houver momentos de experimentação concreta do sujeito, precedida por observação intensa ou pela exposição sistemática de um saber a partir de outrem, normalmente, mais experiente (XAVIER, 2011, p. 5).

Xavier (2011) aponta ainda que o espaço escolar deve ser entendido para além da formalização de conteúdos. "Antes a escola deve ser percebida como um investimento intelectual na construção sociocultural de pessoas a fim de torná-las sujeitos de sua própria história" (XAVIER, 2011, p. 11). Nessa perspectiva, há a necessidade de discutir o objeto de estudo a partir do cotidiano do estudante e, para tal, discutir como inovações metodológicas que levem em consideração a sua realidade podem se mostrar mais efetivas no processo de ensino-aprendizagem.

Há uma diversidade de recursos tecnológicos que podem contribuir para inovações metodológicas dentro do ensino de Ciências, mas é interessante observar quão difícil é a adoção de novas ideias e sua incorporação a práticas concretas em sala de aula. Tal dificuldade está presente nos processos de difusão e incorporação de inovações, mesmo que tais inovações apresentem vantagens em relação à ideia vigente (MÜLLER, 2018). Evidentemente, tal dificuldade não ocorre por ausência de racionalidade, mas, não raro, pelo fato de que tal incorporação exige, da parte de professores muitas vezes sobrecarregados, uma dedicação constante para se manterem atualizados.

A metodologia tradicional, que se fundamenta em aulas expositivas para a resolução de problemas algébricos, com o professor como o protagonista do ensino, está cada vez mais ultrapassada. Santos, Alves e Moret (2006) indicam que um ensino das Ciências, baseado exclusiva ou predominantemente em discursos, transmite uma ideia incompleta e pouco aliciante do que é a ciência e de como ela se constrói. Carvalho (2005) traz uma reflexão sobre o que é preciso para a renovação do ensino de Ciências:

Para uma renovação do ensino de ciências precisamos não só de uma renovação epistemológica dos professores, mas que essa venha acompanhada por uma renovação didático-metodológica de suas aulas. Agora não é só uma questão de tomada de consciência e de discussões epistemológicas, é também necessário um novo posicionamento do professor em suas classes para que os alunos sintam uma sólida coerência entre o falar e o fazer. Este é um ponto bastante complexo, pois os professores, para o desenvolvimento de suas aulas, necessitam de materiais instrucionais coerentes com uma proposta de ensino como investigação o que implica uma renovação também destes programas de atividades (CARVALHO, 2005, p. 10).

A partir do panorama francês, Fourez (2003) também entende que há uma crise no ensino de Ciências. Essa crise se deve a diversos fatores, tanto internos quanto externos à própria área. Todavia, alguns apontamentos devem ser destacados e não podem ficar subnotificados pelos educadores e investigadores, sendo um deles a percepção dos alunos 
sobre a disciplina Ciências em seus currículos, desde o ensino fundamental até o ensino médio. Fourez (2003) explora da seguinte maneira esse aspecto:

Muitos pensam que [...] no centro da crise haveria uma questão de sentido. Os alunos teriam a impressão de que se quer obrigá-los a ver o mundo com os olhos de cientistas. Enquanto o que teria sentido para eles seria um ensino de Ciências que ajudasse a compreender o mundo deles. Isto não quer dizer, absolutamente, que gostariam de permanecer em seu pequeno universo; mas, para que tenham sentido para eles os modelos científicos cujo estudo lhes é imposto, estes modelos deveriam permitir-lhes compreender a "sua" história e o "seu" mundo. Ou seja: os jovens prefeririam cursos de ciências que não sejam centrados sobre os interesses de outros (quer seja a comunidade de cientistas ou o mundo industrial), mas sobre os deles próprios (FOUREZ, 2003, p. 110).

Por sua vez, Vieira (2019) defende que o ensino de Ciências deve dar condições para a formação de cidadãos críticos. A pesquisa faz a seguinte definição de cidadão crítico oportunizada por uma formação adequada e, de fato, consciente dos princípios científicos presentes na área de Ciências:

Tal cidadão crítico é aquele que consegue solucionar os problemas e refletir sobre eles, para uma melhoria do contexto sociocultural no ambiente em que convive. Este cidadão é aquele ser, integrante do ambiente, que se apropria dos conteúdos científicos de forma significativa e contextualizada, concretizando o objetivo de ensinar ciências, indo além de conceitos, apropriando-se da real educação científica (VIEIRA, 2019, p. 1).

Tanto Fourez (2003), a partir do contexto europeu, quanto Carvalho (2005) e Vieira (2019), atuantes no território nacional, concordam que é preciso conduzir o ensino de Ciências de uma maneira mais crítica, contextualizada e, sobretudo, personalizada. São propriedades convocadas na concepção de aprendizagem defendida por Xavier (2011) e que respeitam as características das juventudes da Geração $Y$, conforme a proposta de Rocha-de-Oliveira, Piccinini e Bitencourt (2012). São essas bases que sustentam a perspectiva desta investigação, ao se explorar o ensino de Ciências no (e para) o século XXI.

Este estudo deseja confrontar o que é considerado ensino tradicional de ciências, marcado pelo protagonismo do professor, do saber sistematizado, da técnica e da narrativa unidirecional. No caso da Física, por exemplo, Rosa e Rosa (2005) apresentam a análise de que os textos e, principalmente, os problemas (exercícios, de fato) são apresentados como matemática aplicada, resumidamente na perspectiva de treino do estudante para a resolução de situações algébricas. Em acordo com Borges (1996), Santos, Alves e Moret (2006, p. 84) afirmam que "o ensino tradicional de ciências, do Ensino Fundamental ao Ensino Superior, tem se mostrado pouco eficiente, seja na perspectiva dos estudantes e professores, como nas expectativas da sociedade". 
Freire (1996) faz a seguinte caracterização do que seria o protagonismo do educador na aprendizagem:

Em lugar de comunicar-se, o educador faz "comunicados" e depósitos que os educandos, meras incidências, recebem pacientemente, memorizam e repetem. Eis aí a concepção "bancária" da educação, em que a única margem de ação que se oferece aos educandos é a de receberem os depósitos, guardá-los e arquivá-los. [...] Educador e educandos se arquivam na medida em que, nesta distorcida visão da educação, não há criatividade, não há transformação, não há saber. Só existe saber na invenção, na reinvenção, na busca inquieta, impaciente, permanente, que os homens fazem no mundo, com o mundo e com os outros (FREIRE, 1996, p. 57).

De acordo com Moreira (2018, p. 73), no contexto da Física, “o resultado do ensino tradicional é que os alunos, em vez de desenvolverem uma predisposição para aprender sobre a disciplina, geram uma indisposição tão forte que chegam a dizer que odeiam a Física". Isso se deve a diversos fatores contextuais, condições deficitárias do trabalho docente e também abordagens equivocadas do ensino do ensino de Ciências nas escolas brasileiras - como a predominância do ensino tradicional, na concepção bancária (FREIRE, 1996). O autor faz uma síntese dessas condições com o enfoque na disciplina de Física:

A carga horária semanal [reservada à disciplina de Física no Ensino Médio] que chegou a 6 horas-aula por semana, hoje é de 2 ou menos. Aulas de laboratório praticamente não existem. Faltam professores de Física nas escolas e os que existem são obrigados a treinar os alunos para as provas, para as respostas corretas, ao invés de ensinar Física. A interdisciplinaridade e a transdisciplinaridade são confundidas com não disciplinaridade e tiram a identidade da Física. Os conteúdos curriculares não vão além da Mecânica Clássica e são abordados da maneira mais tradicional possível, totalmente centrada no professor [...] (MOREIRA, 2018, p. 73).

Todos esses são fatores importantes para se compreender o motivo da crise no ensino de ciências, como sugere Fourez (2003), saliente no contexto brasileiro (MOREIRA, 2018). $\mathrm{O}$ aspecto que este estudo coloca em questionamento é o lugar onde ocorre a aprendizagem do aluno no ensino de Ciências. Depreende-se das discussões acima que o protagonismo do educador se mantém e se faz a partir de uma concepção bancária do processo de ensinoaprendizagem, conforme Freire (1994), que é ratificado pelo espaço simbólico e físico em que o professorado é posto diante do alunado.

Para superar esse processo, deve-se propor a formação de cidadãos críticos, como defende Vieira (2019), capazes de produzir seu próprio pensamento, isto é, oportunizar a "transformação mental dentro daquele que aprende" (XAVIER, 2011, p. 5). Este ensaio explora outras dimensões para verificar como se pode enfrentar esse protagonismo do educador e, assim, promover a aprendizagem crítica e significativa no espaço escolar. 
Para apresentar e explorar essa abordagem, retomam-se conceitos do filósofo Michel Foucault (1926-1984), sustentadas, principalmente, em sua obra Vigiar e Punir (FOUCAULT, 1999a). O principal questionamento dessa obra é investigar a história (de fato, a genealogia) da instituição da prisão. Em sua pesquisa filosófica, Foucault (1999) identifica diversos e diferentes mecanismos disciplinares exercidos, regularmente, nas instituições, como o exército, a escola, o hospital, a fábrica e os demais postos de trabalho da época. Ele demonstra as transformações que aconteceram na sociedade para que os indivíduos se tornassem cada vez mais dóceis (socialmente) e produtivos (economicamente). Três principais estratégias são exploradas, no referido estudo, para disciplinar: mecanismos de docilização dos corpos, adestramento e panoptismo. Neste estudo, recupera-se apenas a última estratégia: o panóptico ${ }^{2}$.

Foucault (1999a) cria o conceito de panoptismo a partir da arquitetura. O jurista e filósofo inglês Jeremy Bentham (1748-1832) propôs um modelo idealizado de prisão chamado panóptico, o que Foucault (1999a) entendeu como um símbolo do poder de disciplina na sociedade. O panóptico é uma construção em formato de círculo em que todas as celas estão ao redor de uma torre central. A concepção que subjaz a essa arquitetura é que um preso não veja outro, nem enxergue o vigia. Em contrapartida, o vigia possa ver a todos. A partir dessa figura arquitetônica, Foucault adotou o panoptismo como uma analogia de um poder que está presente, mas é invisível a quem é vigiado e controlado. Semelhante à prisão, no panoptismo foucaultiano, os indivíduos sabem que são vigiados, mas não conseguem notar onde está o vigia.

É preciso esclarecer que Foucault reconhece que o poder de disciplinar os indivíduos não nasce entre os séculos XVII e XVIII, foco de seu estudo, mas é nesse período que há o aprimoramento das técnicas disciplinares, dentre as quais o panoptimo. Qual é a função do panoptismo? Sua função é a de, a partir da reclusão e da vigilância, fixar os indivíduos em grupos e, então, transformá-los em sujeitos disciplinados.

Salienta-se que a disciplina institucionalizada se aperfeiçoa por meio da observação. Em uma análise geral, seria difícil vigiar a todos ao mesmo tempo, mas essa tarefa fica mais fácil quando todos pensam que estão sendo vigiados, mesmo que não se veja o vigia. Esse é o benefício do panoptismo. Conforme Foucault (1999a, p. 87), a instituição vigia quem precisa ser vigiado de acordo com seus objetivos de ação, seja quem for: "[...] uma criança aprendendo, um operário trabalhando, um prisioneiro se corrigindo, um louco atualizando sua loucura [...]". O confinamento cria uma espécie de jogo de poder sobre aqueles que estão presentes (FOUCAULT, 1999b). A vigilância é um dispositivo presente, regulado e coletivizado ou individualizado conforme interesses do regime. Nesse contexto, a arquitetura funciona como um agente opressor que, embora não seja um contribuinte direto da opressão, é planejada para isso, direta ou indiretamente, e, sobretudo, dirigida ao controle dos corpos e das populações (FOUCAULT, 1999c).

Em uma concepção na qual a arquitetura e a organização do ambiente escolar podem ser mais que uma forma de disciplinaridade, este trabalho explora essa dimensão para entender como ela poderia contribuir para a aprendizagem e, em particular, a para a aprendizagem em ciências. Busca-se, então, um ambiente escolar estruturado de forma que estimule o processo

\footnotetext{
${ }^{2}$ Para maiores esclarecimentos sobre esses aspectos, sugere-se a leitura de Foucault (1999a) e de Machado (2007).
} 
de ensino e aprendizagem. Para tanto, adotamos como objetivo deste ensaio investigar como a organização e arquitetura do ambiente escolar podem favorecer a atenção e a concentração dos alunos, em uma perspectiva crítica e significativa.

Para investigar esse aspecto, parte-se de um estudo bibliográfico de caráter exploratório. Este é um ensaio, conforme a definição dada por Adorno (1994) ${ }^{3}$, que prevê tratar do tema do ensino de ciências na perspectiva da cibercultura, isto é, entendendo a cultura das mídias digitais advindas a partir do computador e do acesso à internet (LÉVY, 1993). Adotou-se essa perspectiva para abarcar as juventudes da Geração $Y$ que constituem, atualmente, a base familiar dos alunos matriculados no Ensino Fundamental.

Outros estudos já exploraram o panoptismo foucaultiano aplicado à sala de aula. Por exemplo, Carvalho e Farbiaz (2014) investigam a disciplina na sala de aula a partir do viés da arquitetura e do design, aportando em sua pesquisa o panoptismo, de Foucault (1999a). A alemã Kowaltowski (2011) estuda também a arquitetura escolar e sua correlação com o projeto do ambiente de ensino. Severian (2017), ao retomar Foucault (1999a), examina como o ambiente da sala de aula implica no ensino-aprendizagem de língua estrangeira. Todos esses estudos enfocam aspectos diferentes do panoptismo foucaultiano. Este ensaio enfatiza como esse conceito foucaultiano se aplica às salas de aula de Ciências, considerando a cibercultura.

Teoricamente, este é um estudo interdisciplinar, uma vez que agrega diversas e distintas áreas do conhecimento, produzindo, a partir de seus discursos, um próprio, sem prejuízo à epistemologia de cada área. Metodologicamente, segmentou-se esta investigação em quatro tópicos. No tópico a seguir, discute-se a inteligência coletiva e a zona de desenvolvimento proximal, a partir dos fundamentos teóricos propostos por Lévy (1993) e Vygotski (1988). Em seguida, o segundo tópico aborda a articulação entre ensino de ciências e tecnologias digitais. O terceiro tópico trata da arquitetura no processo de aprendizagem. $\mathrm{O}$ quarto tópico lança duas propostas de ambientes de aprendizagem: a sala de aula articulada e o espaço de colaboração.

\section{InteligênCia Coletiva E ZONA de DESENVOlvimento PROXimal: ENTRE PierRe LÉvy E LeV VygotsKi}

Há uma visão errônea de uma necessária oposição entre o ser humano e a máquina no trabalho e na educação. De acordo com Lévy (1993), a técnica em si não é boa ou ruim, mesmo que dela se inicie a destruição dos sistemas técnicos antigos, que pode ser um dos motivos de alguns identificarem a técnica como uma causa de um mal contemporâneo, quando veem seus valores decaírem. Contudo, quaisquer que sejam os horrores cometidos por armas e máquinas, é a coletividade humana a responsável por tais agressões a si mesma, não uma entidade exterior e separável. Do mesmo modo, não é o celular, o tablet, o computador ou qualquer outro equipamento infotécnico um inimigo natural do processo

\footnotetext{
${ }^{3}$ Para Adorno (1994), o gênero ensaio é um estudo aberto que permite investigar temas candentes e necessários sob à luz de um horizonte aberto à crítica e à discussão de ideias e pensamentos em vigor em determinada época. Portanto, não é um gênero fechado ou que tenda a trazer ideias absolutas. Desse modo, o objetivo deste ensaio é trazer contribuições a partir de ideias já existentes que são reexaminadas sobre novos pontos de vista.
} 
de ensino e aprendizagem, de forma que o que se faz necessário é buscar metodologias e artifícios para que a tecnologia atual seja uma aliada da educação, das mais diversas formas possíveis.

A partir da facilidade de se obter informação em qualquer lugar, um novo paradigma de como tratar o conhecimento e a aprendizagem se estabelece. Vivemos em um tempo em que a informação não está mais confinada nos livros acessíveis por alguns e na mente dos professores (que a dividiam apenas com seus estudantes). A informação é capaz de ser manipulada de maneira cada vez mais eficaz. Assim, torna-se importante observar e analisar como ocorre a absorção de grandes quantidades de informações e em quais condições (SIEMENS, 2005).

A mente não é um todo coerente e harmonioso, mas sim constituída de peças e pedaços. Há duas teses que psicólogos cognitivos prezam: uma é a multiplicidade da mente e outra é o caráter limitado da consciência. Baseados em dados da psicologia cognitiva e as diferentes representações da inteligência nas culturas do mundo, Gardner (1995) propõe que existam cinco inteligências: linguística, espacial, corporal, interpessoal e intrapessoal. A partir dessa concepção de múltiplas inteligências, é possível afirmar que existem diversas e diferentes maneiras de se absorver e capturar as informações e que nenhuma pessoa aprende necessariamente como a outra, uma vez que elas podem ter desenvolvido distintos tipos de inteligência em diferentes graus. Por exemplo, um indivíduo pode ter maior habilidade de se comunicar (inteligências linguística e interpessoal) e outro de dançar (inteligências espacial e corporal). Nem por isso, pode-se dizer que um seja menos ou mais inteligente do que outro, em acordo com a perspectiva de Gardner (1995).

Além disso, vários processos cognitivos são de caráter automático e inconscientes. Esses processos não requerem interpretação de conhecimentos declarativos, não ocupam espaço na memória de trabalho dos indivíduos, liberando o cérebro para atuar em outras tarefas. $\mathrm{O}$ que leva a entender o porquê de um estudante por vezes fazer outras atividades que não o esperado da passividade de ouvir, copiar e reproduzir, calado e em estado contemplativo. É essencial, quando se trabalha com uma geração em que muitos processos cognitivos são automáticos e multifuncionais, a busca de maior estimulação de processos ativos e criativos. O processo de aprendizagem dito tradicional e passivo favorece, então, a não retenção da informação, uma vez que não estimula os processos cognitivos. Isso decorre de diversos fatores biológicos, psicológicos e comportáveis que estão associados aos aspectos psicopedagógicos envolvidos no processo de aprendizagem que podem o influenciar, positiva ou negativamente, conforme sustentam as estudiosas Tabile e Jacometo (2017).

Com relação aos professores, Tabile e Jacometo (2017, p. 79) compreendem que o papel do docente é o de mediação do processo de aprendizagem e, portanto, "o professor também pode ajudar na sistematização dessa aprendizagem, não anulando os conceitos espontâneos, mas utilizando-os como base na aquisição e compreensão dos conceitos científicos". É nesse sentido que o processo de aprendizagem se dá em interação, assim como é influenciado, por diversos fatores, dentre os quais o meio e o social, como defendem os estudos de Lev Vygotski (1896 -1934).

Diferente da teoria de Jean Piaget (1896-1980), em que o desenvolvimento cognitivo provém de dentro para fora por meio do processo de maturação, a proposta de Vygotski afirma que os ambientes podem favorecer ou impedir o desenvolvimento dos processos cognitivos 
- ressalva-se que o estudioso russo continua a considerar o aspecto biológico conjuntamente com os aspectos sociais. Na contramão de Piaget, pode-se dizer que Vygotski postula que o desenvolvimento do processo cognitivo procede mais de fora para dentro do que de dentro para fora. Esse processo de fora para dentro é chamado de internalização que seria a absorção do conhecimento proveniente do contexto em que o indivíduo está inserido/situado.

Para haver essa internalização dos conhecimentos, Vygotski (1998) distingue dois níveis de desenvolvimento: o nível de desenvolvimento real e a zona de desenvolvimento proximal. O primeiro se refere ao desenvolvimento cognitivo em que a criança já tenha galgado, ou seja, é o desenvolvimento de suas funções psicológicas que estão totalmente completas. Já a segunda está relacionada "[...] àquelas funções que ainda não amadureceram, mas que estão em processo de maturação, funções que amadurecerão, mas que estão em estado embrionário" (VYGOTSKI,1988, p. 98). Essa zona de desenvolvimento proximal se constitui como:

[...] a distância entre o nível de desenvolvimento real, que se pode determinar através da solução independente de problemas, e o nível de desenvolvimento potencial, determinado através da solução de problemas sob orientação de um adulto ou em colaboração com companheiros mais capazes". (VYGOTSKY, 1988, p. 97).

É a escola um dos principais espaços dedicados à sistematização do conhecimento, em que o nível de desenvolvimento real se expande porque a zona de desenvolvimento proximal se torna cada vez maior, utilizando os termos de Vygotski (1998). Nela existe um ambiente que proporciona o aprendizado das diversas tecnologias da inteligência ${ }^{4}$. São ensinados os usos das tecnologias intelectuais para proporcionar memórias de curto e longo prazo, as quais estimulam a zona de desenvolvimento proximal. A ativação das memórias de longo período é mais rápida e mais econômica energeticamente, conforme Lévy (1993). Por tal fato, é evidenciado na discussão de Lévy (1993) que há a necessidade de promover mais memórias de longo prazo:

A escola surge ao mesmo tempo que a escrita; sua função ontológica é precisamente a de realizar a fusão íntima de objetos e de sujeitos que permitirá o exercício de uma ou outra versão da "racionalidade". É nela que fazemos da caligrafia e da leitura uma segunda natureza, que as crianças são ensinadas a usar os dicionários, os índices e as tabelas, a decifrar ideogramas, quadros, esquemas e mapas [...] que são exercitadas na manipulação e interpretação dos signos, que aprendem, em suma, a maioria das técnicas da inteligência em uso em uma dada sociedade (LÉVY, 1993, p. 98).

\footnotetext{
${ }^{4}$ De acordo com Lévy (1993), tecnologias da inteligência constituem-se dos instrumentos ou técnicas que, inseridas em seu espaço geográfico-temporal, interagem com as instituições sociais e moldam o pensamento individual e a cognição humana. A escrita, por exemplo, que nas culturas em que foi desenvolvida, permitiu que as sociedades encontrassem outros mecanismos de registro para além da tradição da oralidade e, assim, construíssem uma nova cultura: a cultura da escrita.
} 
Compreende-se, portanto, que a escola é um local de propagação do saber, sendo o espaço privilegiado da educação formal durante a maior parte da infância e adolescência dos indivíduos. Os conhecimentos ensinados, apesar de estarem aprovados e comprovados por diversas comunidades científicas, não são saberes absolutos ou imutáveis. É fácil ver que a escola, como instituição, é uma inteligência coletiva, já que ali são formados e formatados diversos arquétipos, ao mesmo tempo que o pensamento de cada geração foi (re)criado ${ }^{5}$.

Para Lévy (1993, p. 85), “a ecologia cognitiva é o estudo das dimensões técnicas e coletivas da cognição". Tendo em vista que o indivíduo está englobado em um mundo de tecnologias intelectuais, não seria coerente assumir uma individualidade da inteligência. Um julgamento feito sobre um grupo sem distinção dos indivíduos que o compõem seria ingênua diante da complexidade da sociedade global em que vivemos. É preciso o hábito de pensar as pessoas como grupos e sociedades. Sobre a desconstrução do indivíduo, a inteligência é um resultado de uma rede na qual se interligam fatores biológicos, sentimentais e tecnológicos. Daí a importância do conceito de zona de desenvolvimento proximal, pois esta é estimulada pelas interações entre os indivíduos.

É também esse caminho de inter-relacionamento dos diversos perfis do ser humano inserido em sociedade que o estudioso Lévy (1993) explora. Sua proposta é a construção de um meio em que não há mais sujeitos ou objetos pensantes em separado, mas o pensamento se daria em rede, isto é, cognições, atitudes e ideias partiriam da construção inter-relacionada e interdependente dos membros de um coletivo. Seguindo esse raciocínio, por mais que um indivíduo tente se individualizar, essa aparente individualidade seria um mero produto de um pensamento e/ou de uma inteligência, o qual, em essência, derivaria do coletivo. Conforme Fontana e Cruz (1997), o educando desde a tenra idade tem a necessidade de interagir para aprender:

Para consolidar e dominar autonomamente as atividades e operações culturais, a criança necessita da mediação do outro. O mero contato da criança com os objetos de conhecimento ou mesmo sua imersão em ambientes informadores e estimuladores não garante a aprendizagem nem promove necessariamente o desenvolvimento, uma vez que ela não tem, como indivíduo, instrumentos para organizar ou recriar sozinha o processo cultural (FONTANA; CRUZ, 1997, p. 65).

Nesse sentido, trabalhar a coletividade nos espaços de aprendizagem - respeitando as particularidades ali presentes, isto é, as peculiaridades biológicas e emocionais de cada inteligência (GARDNIER, 1995) - faz com que talvez se consiga chegar no todo que está em cada ser. Em outras palavras, a construção do conhecimento não se dá no âmbito do indivíduo isolado e de modo caótico. Longe disso, seguindo essa proposta de conhecimento em rede e avizinhando-a do conceito de zona desenvolvimento proximal ${ }^{6}$, de Vygotski (1988),

\footnotetext{
${ }^{5}$ Para maiores informações sobre o conceito de arquétipo, consulte a obra de Jung et al. (2016).

${ }^{6}$ Conforme Vygotski (1988), temos, pelo menos, duas zonas de desenvolvimento do processo cognitivo: a real e a proximal. "A zona de desenvolvimento proximal define aquelas funções que ainda não amadureceram, mas que estão em processo de maturação, funções que amadurecerão, mas que estão presentemente em estado embrionário. Essas funções poderiam ser chamadas de "brotos"ou "flores"do desenvolvimento, ao
} 
depreende-se que os espaços de aprendizagem são constructos que se erguem à medida que ocorrem as interações. Quanto maior a rede, mais interações e, consequentemente, mais se expande a zona de desenvolvimento proximal, acarretando em um maior espaço de aprendizagem. Eis como o conhecimento em rede se relaciona com o desenvolvimento do conhecimento e, portanto, ratifica o conceito de Lévy (1993) de inteligência coletiva.

\section{A ARTICULAÇÃO ENTRE ENSINO DE CIÊNCIAS E TECNOLOGIAS DiGITAIS}

No ensino das Ciências, disciplinas que abordam o estudo de diversos fenômenos, percebe-se, muitas das vezes, uma tendência em explicar o temário das aulas em um viés abstrato. Lévy (1993, p. 97) crítica esse tipo de abordagem sobre os fenômenos, uma vez que "um problema que permanecesse abstrato seria simplesmente insolúvel". Além disso, um aluno que não interage com o assunto tem maior dificuldade de atingir os objetivos de aprendizagem. Assim, se o professor tem o interesse de implementar o ensino de um conteúdo com o uso de tecnologias que promovam interação do aluno com a matéria, o docente deve fazer com que o alunado apre(e)nda o uso das tecnologias para além de uma ferramenta física, mas como um instrumento simbólico (VYGOTSKI, 1988).

De acordo com Sforni e Galuch (2009), Vygotski (1988) lança a expressão instrumento simbólico para deslindar a fronteira entre as funções dos signos e dos instrumentos físicos que são criações essencialmente humanas:

o termo instrumento simbólico é uma analogia feita por Vygotski sobre a função de duas criações humanas: os signos e os instrumentos físicos. Ao mesmo tempo em que o homem cria os instrumentos materiais que lhe permitem maior domínio sobre a natureza, cria também os meios artificiais que lhe possibilitam controlar a sua própria conduta. (SFORNI; GALUCH, 2009, p. 80-81, grifo nosso).

Seguindo a reflexão de Vygotski (1988), a mediação entre a humanidade e o conhecimento é de ordem simbólica. Oliveira (2008, p. 26) explica, por sua vez, que cada ser humano "tem a possibilidade de pensar em objetos ausentes, imaginar eventos nunca vistos, planejar ações a serem realizadas em momentos posteriores". Em outros termos, no caso da escolarização, o educando pode dar sentido a objetos, lugares e situações quando consegue convencionar uma forma de significado para esses elementos. Isso decorre, porque, conforme aponta Vygotski (1988), ao se confrontar com uma informação nova, o ser humano pode dar diferentes respostas a depender de sua memória, de suas vivências e das convenções estabelecidas. Daí a importância que o professor tem ao atribuir para as tecnologias novos significados que não estão necessariamente encerrados no seu modo de uso ou na estrutura física de cada objeto, transformando-os, assim, em instrumentos simbólicos.

invés de "frutos"do desenvolvimento. O nível de desenvolvimento real caracteriza o desenvolvimento mental retrospectivamente, enquanto a zona de desenvolvimento proximal caracteriza o desenvolvimento mental prospectivamente" (VYGOTSKI, 1988, p. 58). 
Diante da difusão das Tecnologias Digitais de Informação e Comunicação (TDIC), é necessário pensar a atividade docente em integração com essas tecnologias, pois, em sociedade, o seu uso é massivo e, portanto, a Educação Básica que pretende formar para a vida deve se comprometer com o ensino e a aprendizagem de novas tecnologias, em especial aquelas que o alunado, por diversos motivos, pode ter dificuldade de acesso - como a internet de banda larga e os computadores. Dentre as possibilidades de integração entre TDIC e conteúdos escolares, pode-se citar: (a) a simulação de um problema a partir da gamificação, para a melhor visualização do conteúdo em diversas realidades e contextos, propiciados pelos cenários e objetivos de cada etapa do jogo; (b) a interpretação e a manipulação do tema a partir da simulação virtualizada de diversos contextos por meio da realidade virtual; (c) a exploração de temáticas interdisciplinares a partir de pesquisa em bases e fontes digitais. As TDIC possuem grande potencial de ressignificar o processo de ensino-aprendizagem à medida que incluem informações de diferentes formatos à aula.

Levando em consideração a adoção de novas metodologias de ensino e os processos cognitivos dos participantes no processo de aprendizagem, as TDIC podem ampliar a possibilidade de aprendizagem ativa, privilegiando o aprendizado autônomo, a investigação, a reflexão crítica acerca dos conteúdos e a resolução de problemas. Espera-se efetivamente que as tecnologias façam parte da aula de forma articulada ao longo de todo o processo educativo. Abordagens como a Instrução por Pares (MAZUR, 2015) e o Ensino sob Medida (NOVAK et al., 1999) se mostram relevantes nesse cenário de abundância de informações e de possibilidade de acesso às tecnologias.

Destaca-se que não se pode restringir a funcionalidade das tecnologias a um instrumento no processo de transmissão de informações, como uma projeção de slides ou questionários virtuais. Nem mesmo deve ocorrer que os materiais didáticos sejam os mesmos apresentados tradicionalmente, mas em uma versão digitalizada, não incluindo possibilidades multimídias e hipertextuais da rede digital. As TDIC são, mais do que facilitadoras, parte integrante do desenvolvimento de uma metodologia ativa de aprendizagem. Nesse sentido, essas ferramentas devem ser pensadas juntamente aos objetivos do plano de aula, estratégias e avaliação, de forma coerente e coesa, mas que não deva estar associado a apenas uma aula específica dentro de um programa de ensino, porque existe a possibilidade de se tornar uma atividade lúdica sem compromisso com o resultado do processo de aprendizagem da disciplina, em especial a de Ciências, que exige uma articulação entre os conteúdos e os fenômenos naturais.

De acordo com Moreira (1998), a educação em ciências tem por objetivo fazer com que o aluno venha a compartilhar significados no contexto das Ciências, ou seja, interpretar o mundo pelo ponto de vista das Ciências, manejar alguns conceitos, compreender as leis e as teorias científicas, abordar problemas raciocinando de forma lógica, identificar aspectos históricos, epistemológicos, sociais e culturais das Ciências. Entretanto, a metodologia tradicional de ensino de Ciências - em especial em Física, essa tendência é bastante perceptível no Ensino Médio - não se ousa adentrar em abordagens que associam o potencial das TDIC aos conteúdos da disciplina. Com efeito, materiais didáticos digitais (como simuladores, vídeos, plataformas digitais, equipamentos como tablets, quadros-interativos, dentre outros) são de grande importância para a criação de bons modelos mentais, uma vez que permitem a internalização, no sentido dado por Vygotski (1998), dos modelos físicos e matemáticos 
- por muitas vezes considerados abstratos pelos estudantes. Para que essa internalização ocorra, as TDIC não podem ser entendidas pelos professores como instrumentos físicos, mas ensinadas como instrumentos simbólicos que (re)criam os sentidos e os significados dos conteúdos. É nesse sentido que as TDIC deixam ser uma ferramenta para se integrarem ao processo de ensino e aprendizagem.

Outra vantagem das tecnologias associadas ao ensino é permitir que o estudante interaja com a tecnologia dentro e fora de sala, o que pode melhorar sua aprendizagem e ser valioso em múltiplas abordagens didáticas. Por exemplo, o paradigma do ensino híbrido se constitui como a articulação entre a modalidade presencial e a distância em um processo de intercâmbio de conhecimentos e práticas. Esse tipo de ensino é facilitado pelo uso de dispositivos eletrônicos móveis (SUNAGA; CARVALHO, 2015). Aplicativos podem, portanto, atrelar-se ao processo educativo, dentro e fora da sala, de modo que as TDIC não sejam uma ferramenta, mas parte da própria abordagem de ensino-aprendizagem.

Ademais, no modelo de ensino híbrido, existe a possibilidade de se realizar atividades de disciplinas presenciais em diversas situações não formais de educação. Por exemplo, é possível realizar atividades durante o translado de casa para a instituição de ensino, ou mesmo em ambientes nos quais não há computadores à disposição, como em um parque, a casa de um colega ou um ambiente da própria instituição em que o estudante está esperando para realizar uma outra atividade. Todas essas situações permitem o acesso e a realização de atividades educativas desde que o aluno tenha em mãos uma tecnologia digital. É nesse caminho que o ensino híbrido nos leva a entender as TDIC para além de seu uso como ferramenteiro, entendendo-as como portais de acesso à informação e à formação assíncrona.

A metodologia de ensino híbrido e a sala de aula invertida - dentre outras - são abordagens já utilizadas e validadas em diversas configurações de aprendizagem no Ensino Superior (BERGMANN; SAMS, 2018; MANZUR, 2015; VALENTE, 2014). Elas constituem metodologias ativas, isto é, que estimulam a ação e a interação por meio de TDIC em consonância com a finalidade pedagógica. As metodologias ativas oportunizam a integração com os dispositivos eletrônicos, em especial os móveis, e incentivam que o processo de ensino-aprendizagem ocorra em locais não necessariamente formais de ensino-aprendizagem como cômodos da casa (quarto, cozinha, sala de estar etc.), locais públicos (parques, praças, quadras etc.) e outros espaços.

Seja utilizando as TDIC como meio de acesso (permitindo que se apresentem situações e experimentos que não seriam possíveis de se fazer tradicionalmente) ou como meio de interação (como o uso de fóruns de discussão e testes on-line, expandindo a aprendizagem), as tecnologias digitais superam barreiras naturais de aprendizado, como distância e recursos. Se em uma aula de Ciências, por exemplo, falta o aparato experimental necessário para tratar um tema de maneira prática; ou se o experimento é perigoso; ou ainda, se demora demais para ser executado ou se é extremamente rápido; em todas essas situações ainda é possível simular esse experimento de maneira virtual em softwares específicos, suprindo, assim, as dificuldades que normalmente poderiam impedir a realização da atividade didáticopedagógica.

Como se pode apreender, as TDIC são relevantes para o processo de ensino-aprendizagem quando as apreendemos como instrumentos simbólicos e não mais como meros instrumentos físicos. Como meio de acesso de interação, as TDIC já fazem parte de distintas metodologias 
ativas. O ensino de Ciências, como foi exposto, pode ter seus objetivos atendidos quando, de fato, as TDIC forem ressignificadas na perspectiva do professorado e em suas práticas com o alunado. Do físico para o simbólico, eis o percurso proposto para essa ressignificação.

\section{A ARQUITETURA NO PROCESSO DE APRENDIZAGEM}

Retomando a historicidade da arquitetura do espaço escolar, destaca-se que a preocupação com as formas do ambiente de aprendizagem só começou por volta do século XX, com o movimento da Escola Nova que, dividindo espaço com o modelo tradicional vigente, pensava no ambiente escolar como fonte de desenvolvimento pessoal e individual. Alguns dos pensadores desse movimento começaram a escrever sobre as relações entre as atividades de suas pedagogias e o ambiente. Como explica Künzle (2007), nota-se a presença de duas vertentes de organização do ambiente escolar: a tradicional e a da Escola Nova.

A organização tradicional foi chamada por Foucault (1999a) de panóptica, pois era um ambiente austero, disciplinado, silencioso, constituindo-se, assim, como uma espécie de máquina de hierarquizar, ensinar e vigiar, que moldava o comportamento dos indivíduos. Pode-se verificar o funcionamento desse maquinário na descrição que o filósofo faz do sistema escolar a partir da ordenação por fileira no século XVIII:

A ordenação por fileira, no século XVIII, começa a definir a grande forma de repartição dos indivíduos na ordem escolar: filas de alunos na sala, nos corredores, nos pátios; colocação atribuída a cada um em relação a cada tarefa e cada prova; colocação que ele obtém de semana em semana, de mês em mês, de ano em ano; alinhamento das classes de idade umas depois das outras; sucessão dos assuntos ensinados, das questões tratadas segundo uma ordem de dificuldade crescente. E nesse conjunto de alinhamentos obrigatórios, cada aluno segundo sua idade, seus desempenhos, seu comportamento, ocupa ora uma fila, ora outra; ele se desloca o tempo todo numa série de casas; umas ideais, que marcam uma hierarquia do saber ou das capacidades, outras devendo traduzir materialmente no espaço da classe ou do colégio essa repartição de valores ou dos méritos. Movimento perpétuo onde os indivíduos substituem uns aos outros, num espaço escondido por intervalos alinhados (FOUCAULT, 1999a, p. 134).

Associado ao espaço, está o tempo. Foucault (1999a) aponta que a experiência do tempo também é (trans)formada no sistema panóptico, contribuindo, assim, para a disciplinaridade e o poder de controle sobre os corpos e seus comportamentos. É o tempo disciplinar:

Esse é o tempo disciplinar que se impõe pouco a pouco à prática pedagógica especializando o tempo de formação e destacando-o do tempo adulto, do tempo do ofício adquirido; organizando diversos estágios separados uns dos outros por provas graduadas; determinando programas, que devem desenrolar-se cada um durante uma determinada fase, e que comportam 
exercícios de dificuldade crescente; qualificando os indivíduos de acordo com a maneira como percorreram essas séries (FOUCAULT, 1999a, p. 144).

Frago e Escolano (2001, p. 63) explicam que "são muitas as influências e entrecruzamentos entre o espaço e o tempo". Nesse sentido, os estudiosos salientam que a noção de memória é decorrente da "recordação de espaços diversos ou de fixações diferentes de um mesmo espaço" (FRAGO; ESCOLANO, 2001, p. 63). Pode-se, assim, entender que a memória constitua, em linhas gerais, um depósito de imagens, sensações e reflexos ancorados na relação com os espaços, os quais, por sua vez, se tornaram, dentro da mente, lugares de memória. Nas palavras de Frago e Escolano (2001, p. 63), estes são "lugares nos quais algo de nós ali ficou e que, portanto, nos pertencem; que são, portanto, nossa história". Portanto, quando Foucault (1999a) aponta a relação entre espaço e tempo e sua função disciplinar nos comportamentos dos indivíduos, podemos depreender, apoiados na reflexão de Frago e Escolano (2001), que o espaço panóptico e o tempo disciplinar, associados e inseridos nos espaços escolares, fazem com que as memórias dos indivíduos sejam afetadas, criando os lugares de memória da disciplinaridade.

Quando se tem essa compreensão sobre o espaço escolar e sua influência na memória dos indivíduos, não se pode negligenciar a importância da arquitetura escolar na formação dos educandos. Atualmente, essa temática não recebe a devida atenção por parte dos arquitetos e dos especialistas da área da Educação, conforme expõem Arrais Neto, Ricca e Souza (2016, p. 138):

A problemática da Arquitetura Escolar foi negligenciada, de maneira geral, tanto nos estudos teóricos de arquitetura e na formação dos arquitetos, quanto no processo de formação dos educadores, tendo repercussão na forma como o sistema escolar brasileiro pouco ou nada discutiu da relação pedagógica do espaço escolar e da importância educativa da edificação e de sua concepção arquitetônica. Enfocada apenas quando do desenvolvimento de arquitetura escolar para a educação infantil ou, no máximo de ampliação, da concepção de espaços escolares destinados à primeira etapa do ensino fundamental (primeiro ao quinto ano), a compreensão assentada tanto nas secretarias de educação (estados e municípios) quanto no senso comum da área de educação e pedagogia parece limitar a relação entre currículo e arquitetura ao espaço voltado à educação de crianças.

Entende-se, portanto, que está equivocado o pensamento de que a importância visual e interativa que a arquitetura escolar pode oferecer para o aluno só se faz necessária nos períodos mais lúdicos da vida. Künzle (2010) afirma que a arquitetura, se devidamente considerada no contexto da sala de aula, torna-se uma grande contribuição para o processamento de informações, captação de recursos conceituais e na habilidade de percepção dos alunos. Dessa forma, o que se percebe do sistema educacional brasileiro é que ainda falta mais estudos que valorizem os aspectos físicos e ambientais de uma sala de aprendizagem, pois, como estamos apontando, essas características físicas podem agregar aos métodos de 
ensino e ao processo de aprendizagem.

O ambiente, de maneira geral, é uma variável expressiva no processo de aprendizagem e construção das memórias (FRAGO; ESCOLANO, 2001). No processo de assimilação, as variáveis apresentadas no meio (como imagens e sons) geram associações de conceitos abstratos com aspectos visuais e impressões provocadas pelo ambiente. Essas associações geram certos links de memória que associam os conhecimentos novos a sentidos menos abstratos (LÉVY, 1993).

Em outras palavras, uma sala de aula, se devidamente planejada junto com as possíveis atividades a serem desenvolvidas, contribui para diversos fatores: (a) a construção do pensamento; (b) a organização dos grupos; (c) a condução metodológica da proposta didático-pedagógica; (d) a disposição dos recursos no ambiente; (e) a construção de uma rede complexa de hipertextos ${ }^{7}$. Como consequência, há uma maior variedade de maneiras com que os conhecimentos prévios podem ser articulados à nova informação apresentada, por ter um número muito maior de ideias circulando pelo ambiente - isto é, o próprio ambiente favorece o processo de memorização e retenção das informações. Quando o ambiente acolhe as informações e as reflete e as refrata, o próprio espaço facilita a fixação dos conceitos - desde os mais abstratos até os mais concretos. Com isso, o ambiente se torna parte integrante do processo de construção de uma aprendizagem mais efetiva, abrangendo mais formas de pensar e revisitar os conteúdos pedagógicos.

Para que o ambiente escolar contribua com a aprendizagem, é preciso que o espaço seja estruturado de forma a favorecer a atenção e a concentração, mas, diferentemente da construção panóptica que cerceia a criatividade e a construção de novas ideias, o espaço escolar pode se tornar um ambiente restaurador, nos termos de Kaplan (1995). Retomando os estudos de Kaplan e Kaplan (1989) e Kaplan, Kaplan e Ryan (1998), Bernardes (2018, p. 25) define que "um ambiente restaurador é aquele que promove ou permite a restauração dos recursos dos indivíduos, sejam eles biológicos, ou psicológicos, necessários para uma adaptação bem-sucedida às circunstâncias atuais [...]".

Destaca-se que, desde os anos de 1980, a Teoria da Restauração da Atenção (tradução de Attention Restoration Theory) tem examinado como os aspectos do ambiente físico podem propiciar ou não a maior recuperação da capacidade humana de atenção dirigida, a qual pode estar mais ou menos fragilizada durante as atividades (KAPLAN; KAPLAN, 1989; KAPLAN, 1995) ${ }^{8}$. Concorda-se que, "tendo em vista a importância da atenção no processo de aprendizado (prestar atenção no professor, manter a atenção em tarefas escolares, ignorar estímulos externos), entende-se que este aspecto deve ser considerado na concepção de ambientes escolares" (BERNARDES, 2018, p. 25-26).

A partir desses aportes teóricos, entende-se que o conceito de ambiente restaurador é compatível com a proposta pedagógica do processo de ensino-aprendizagem, bem como traz contribuições para o espaço escolar. Esse conceito pode promover a integração entre a arquitetura escolar e os recursos biológicos, psicológicos e sociais dos indivíduos. Em

\footnotetext{
${ }^{7}$ Pierre Lévy (1993) define o hipertexto como uma forma de caracterizar o funcionamento da mente a nível das associações que ocorrem entre um input de ideia com a rede de conhecimentos. O conceito se aproxima das estruturas cognitivas de David Ausubel (1968), ainda que possua propriedades mais dinâmicas e abstratas associadas.

${ }^{8}$ Para maiores informações sobre essa teoria, indica-se a leitura de Gressler e Günther (2013).
} 
outras palavras, é necessário humanizar a sala de aula, adequando-a às práticas didáticopedagógicas e permitindo desde a livre manipulação do mobiliário até a associação entre espaço físico e memória (FRAGO; ESCOLANO, 2001). Com isso, efetivar-se-á a criação de links e hiperlinks (LÉVY, 1993) que estimularão a aprendizagem significativa (AUSUBEL, 1968).

Ainda quanto ao aspecto restaurador, Bernardes (2018) acredita que os ambientes naturais possuem maior qualidade física para a recuperação da atenção. Empregar paisagismo no ambiente de ensino é essencial para harmonizar o ambiente natural e o construído, isto é, fazer a passagem das ferramentas físicas para os instrumentos simbólicos (VYGOTSKI, 1988). Nesse sentido, torna-se necessário renovar ambientes educacionais regularmente, pois os usuários passam a sentir descontentamento e desmotivação, devido ao desgaste e desatualização do espaço físico. Por exemplo, iluminação inadequada, além de diminuir a produtividade dos usuários, pode ser responsável por provocar a fadiga e a maior irritabilidade ocular (ALVES, 2014).

Considerando esse conceito, pode-se aplicá-lo ao cotidiano escolar fazendo algumas modificações, tanto no ambiente físico, quanto no uso dos recursos e instrumentos físicos. Sanoff et al. (2001) propõem os seguintes princípios para o projeto escolar se tornar mais propício para o processo de ensino-aprendizagem: (a) construir de um ambiente estimulante; (b) propiciar um lugar para ensino em grupo; (c) conectar o interior com o exterior, fazendo, por exemplo, que as áreas públicas sejam incorporadas ao espaço escolar; (d) transmitir segurança aos visitantes e aos membros da unidade; (e) estimular uma variedade espacial, permitindo modificações e maior flexibilidade e riqueza de recursos físicos; (f) equilibrar espaços personalizados com espaços comunitários. Partindo desses princípios, os estudiosos compreendem que a sala de aula deve ser projetada para que o ambiente físico comporte as atividades desenvolvidas, no que tange às demandas de professores, estudantes e visitantes. Sanoff et al. (2001) entendem que, mesmo não existindo um arranjo físico ideal para os móveis das salas de aula, o espaço escolar deve, por essência, promover uma maior flexibilidade que permita que os móveis e os recursos físicos sejam adaptados à realização de diferentes atividades, as quais devem ser coerentes a cada conteúdo programático e grupo de indivíduos.

Essa complexidade do edifício escolar, com vários aspectos e necessidades diferentes, faz com que a arquitetura escolar seja repensada no século XXI (KOWALTOWSKI, 2011). Entendendo as inter-relações que se estabelecem entre um espaço e um tempo, nota-se a memória que cada lugar guarda e transmite. É nesse sentido que o instrumento simbólico (VYGOSTSKI, 1988) se fortalece em detrimento do que era reconhecido como meramente físico. A concretude e fisicalidade dos recursos que compõem o ambiente escolar ganham novos matizes teóricos, porque, na contramão do efeito panóptico e do tempo disciplinar (FOUCAULT, 1999a), pode-se apreender um ambiente restaurador (BERNARDES, 2018; KAPLAN, 1995) que possibilita os links e os hiperlinks (LÉVY, 1993) que estimulam a aprendizagem significativa (AUSUBEL, 1968). 


\section{Propostas de ambientes de aprendizagem no Contexto DA CIBERCULTURA}

Seguindo a proposta de projeto escolar de Sanoff et al. (2001), propõem-se espaços que enlaçam a mobilidade com a atratividade do ambiente, fortalecendo a proposta didáticopedagógica e a interação professor-aluno. São espaços pensados para a utilização de equipamentos de TDIC e a adoção de metodologias de aprendizagem que estimulam diversas inteligências (GARDNER, 1995), reforçados pela grande mobilidade entre os estudantes e o professorado dentro do espaço físico. Sanoff et al. $(2001$, p. 1) compreendem que o ambiente físico pode ser entendido "como o segundo professor, uma vez que o espaço tem o poder de organizar e promover relações agradáveis entre pessoas de diferentes idades, promover mudanças, promover escolhas e atividades e por seu potencial por estimular diferentes tipos de aprendizado social, cognitivo e afetivo". Isso ocorre, porque, segundo os autores, "o espaço dentro da escola reflete as ideias, valores, atitudes e culturas das pessoas dentro dele" (SANOFF et al., 2001, p. 1). Partindo dessas reflexões, exploramos as seguintes propostas de ambientes de aprendizagem no contexto da cibercultura: sala de aula articulada e espaços de colaboração.

\section{V.1. sala de aula articulada}

Mesmo com os avanços tecnológicos e científicos, a sala de aula tem sido um ambiente que permanece há muito sem mudanças, sendo a maioria estruturada com o layout tradicional (carteiras enfileiradas seguindo o padrão de linhas de produção), centrado no professor e na passividade do aluno. Para fugir do padrão panóptico foucaultiano, propõe-se uma sala de aula com mesas ditas modulares, o que constitui o ponto fulcral do que denominamos sala de aula articulada.

Mesas modulares são mesas de formatos variados com o objetivo de serem usadas em diversas configurações. Elas podem ser postas em salas de forma individual, em dupla ou em grupos. Seu formato possibilita um acoplamento entre as mesas para uma maior mobilidade e flexibilidade de arranjos. São úteis, ainda, em comportar qualquer atividade proposta pelo professorado no que se refere à distribuição em um espaço, pois cada uma pode se encaixar em grupos ou se dispor de forma isolada, formando, assim, distintos layouts em um mesmo espaço. Um exemplo de mesas modulares são as trapezoidais individuais. O formato de trapézio possibilita encaixes diversos entre seus lados. Na figura 1, podem-se contemplar alguns dos arranjos possíveis de mesas modulares em formato de trapezoide.

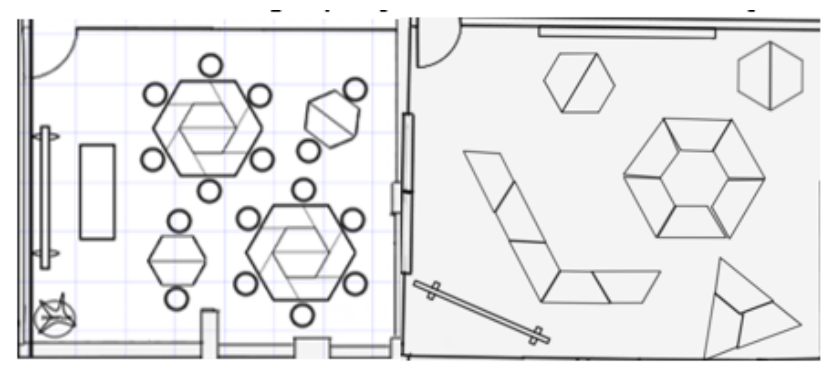

Figura 1: Fonte: Elaboração dos autores. 
Como se pode apreender, o formato de trapezoide permite que se formem diferentes agrupamentos (duplas, trios, quartetos etc.) e em distintos formatos (triângulos, hexágonos, linhas etc.). Esse tipo de mesa incentiva a criatividade e, assim, estimula que os grupos de estudantes sejam distribuídos de diferentes maneiras. Cada aula pode proporcionar uma nova experiência de agrupamento, facilitando a comunicação entre os indivíduos de um grupo e, consequentemente, estreitando o laço afetivo entre eles.

Também é válido apontar a qualidade física de ambientes naturais para a recuperação da atenção, como tratado por Bernardes (2018). Empregar paisagismo no ambiente se torna essencial para harmonizar o natural e o construído. Nesse sentido, é interessante incluir algum tipo de paisagismo que contribua com o conforto visual do ambiente. Podem ser colocadas plantas ou também podem ser inseridas figuras simbólicas que façam os usuários desse espaço refletir sobre a própria constituição orgânica e inorgânica dos móveis que constituem esses espaços. Assim, como Borges (1996) reivindica, o laboratório de Ciências não seria mais o local exclusivo em que se desafia a percepção do alunado para os fatos do cotidiano. A didática da disciplina, como um todo, poderia ser revisitada à luz da sala de aula articulada, tanto em seu aspecto físico (mesas modulares), quanto em sua proposta didática (interação entre natural e o construído).

\section{V.2. Espaço de colaboração}

O segundo espaço aqui proposto é aberto para a circulação de pessoas. Essa abertura tem o intuito de desenvolver projetos em colaboração. Esses espaços são, recentemente, conhecidos na esfera do trabalho pela expressão inglesa coworking que, segundo Medina e Krawulski (2015, p. 181), pode ser entendida como "uma modalidade sob a qual profissionais de diferentes áreas, em busca de enriquecer sua rede de contatos e/ou por não possuírem um local fixo de trabalho, compartilham o mesmo ambiente e serviços de escritório". Segundo as autoras, é um fenômeno bastante recente no Brasil, mas que segue a tendência mundial e está em crescimento, sobretudo, nas grandes capitais ${ }^{9}$. Do conceito de coworking, a proposta de espaço de colaboração absorve as práticas de compartilhamento de espaço e ferramentas.

Os espaços de colaboração seriam compartilhados pelas diferentes turmas e séries/anos da unidade escolar. Esse compartilhamento pode ser ordenado por escalas horárias, respeitando a proposta de tempos comunitários (turmas diferentes juntas) e tempos personalizados (uma turma por vez). Essa organização de funcionamento vai depender das necessidades e das peculiaridades de cada unidade escolar. Portanto, um espaço de colaboração não é necessariamente uma sala de aula, mas um espaço aberto para as experimentações pedagógicas.

Outra característica do espaço de colaboração seria o acesso aos recursos. Cada um desses espaços comportaria uma grande quantidade de recursos digitais que poderiam ser utilizados por diversos alunos e professores. Esse ambiente forneceria materiais didáticos

\footnotetext{
9“O coworking ainda é fenômeno recente no Brasil: os primeiros movimentos de implementação dessa iniciativa em nosso país datam de 2007, mostrando-se como tendência cada vez maior no mercado de trabalho atual. Desde então, o coworking divulga entre suas vantagens o baixo custo e o fornecimento de uma estrutura adequada para atender pequenas empresas, autônomos, freelancers, empresários emergentes e teletrabalhadores" (MEDINA; KRAWULSKI, 2015, p. 182).
} 
(livros, apostilas, cartolinas etc.) e informáticos (lousa digital, notebooks, tablets etc.). Indicase fortemente a preferência pelos dispositivos digitais leves e de fácil mobilidade, como, por exemplo, os tablets, pois esse formato colabora com a flexibilidade da configuração do espaço $^{10}$.

Segundo Bernardes (2018), é preciso considerar que o aprendizado não ocorre de forma passiva, mas por meio da (inter)ação com colegas e com professores. Ainda segundo a autora, a apatia em sala de aula deve-se à distância física e à pouca flexibilidade nos processos de comunicação e discussão de conteúdo. Com tal pensamento, indicam-se mesas grandes que possam servir para o debate de ideias e também para o encontro visual entre os usuários.

Outro aspecto a ser discutido é o ajuste do layout do ambiente. Para Kowaltowski (2001), o layout de um ambiente escolar vai muito além da organização do mobiliário. Para estudiosa, o layout revela o aproveitamento do espaço que pode ser traduzido em economia de tempo, bem como de melhoramento do processo produtivo, da segurança e do conforto dos usuários daquele espaço.

Considerando esses pressupostos, na figura 2, há a proposta de configuração do espaço de colaboração. Nesse local, existe a presença de uma lousa digital e um projetor para situar melhor a interação dos estudantes no projeto. A disposição dos móveis não é linear, mas circular. O professor não está na parte frontal, mas sua mesa se localiza no centro - o que não necessariamente significa que o docente ali permanecerá durante toda aula ${ }^{11}$. Uma das características desse projeto arquitetônico é que existam, pelo menos, duas portas, o que já se confronta com o espaço panóptico que concentra a entrada e a saída em um único portal. Podemos observar a figura a seguir:

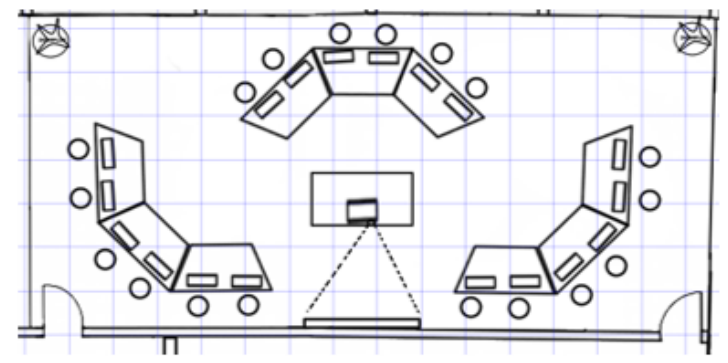

Figura 2: Fonte: Elaboração dos autores.

Esse ambiente poderia ser utilizado para projetos-solo, em conjunto e/ou para o ensino. Poderia também ser utilizado para produzir materiais interativos em formato de vídeo como videoaulas. As possibilidades são diversas. O formato circular, a disposição de TDIC, a projeção em formato de arena, dentre outros aspectos desse layout, faz com que os usuários desse espaço se sintam livres para o exercício do debate. Todos podem se ver e assim interagir. As portas estão abertas para entrar e sair. Além disso, as tecnologias digitais, dentro desse modo, estão integradas ao processo de ensino e aprendizagem.

\footnotetext{
${ }^{10}$ Para maiores informações sobre o uso de tablets na sala de aula, recomenda-se a leitura de Souza (2015).

${ }^{11} \mathrm{~A}$ proposta é que o centro seja ocupado tanto pelo professor quanto pelo aluno em diferentes momentos da aula. Com isso, evita-se a concentração da atenção na figura do professorado. A proposta é o compartilhamento dos espaços, como está no cerne da ideia de coworking.
} 
Esse modelo tem bastante espaço para que, dependendo da adoção, seja possível moldar a quantidade de recursos para o que se busca no cômodo, isto é, as mesas e as cadeiras não são fixas, elas podem mudar de lugar - como na sala de aula articulada, são mesas modulares. A projeção não deve servir apenas como parte ilustrativa da exposição do docente, mas para outras finalidades didático-pedagógicas. A flexibilidade e a mobilidades são premissas que devem imperar em espaços de colaboração. Por exemplo, esse espaço permite que se formem ilhas de desenvolvimento, isto é, pequenos agrupamentos com metas e objetivos definidos dentro de um projeto. Tais ilhas podem ser feitas com mesas unitárias ou com o encontro delas, por isso é importante que as mesas tenham mobilidade com os fios e com os computadores.

Outro detalhe desse modelo é que as paredes podem ser equipadas com antirruído e a sala pode apresentar uma iluminação com controle de regiões (pois haveria um suporte de um projetor no local). A inserção desses detalhes poderia proporcionar uma significativa melhoria no bem-estar dos usuários - eis uma sugestão para que essa proposta teórica seja aplicada em estudos empíricos ulteriores e essa hipótese seja, assim, testada. Também é recomendável que os fios das máquinas não atrapalhem a circulação do ambiente, fazendo necessário a inclusão de um piso flutuante que comporte os cabos imediatamente abaixo das mesas.

De forma geral, é importante enfatizar que deve se levar em conta o que foi abordado sobre a utilização das TDIC de forma coerente e pensada no planejamento da aula. O intuito desses espaços não abrange apenas a experiência lúdica, mas também o acolhimento das TDIC como instrumentos simbólicos no desenvolvimento cognitivo dos estudantes, na esteira da proposta de Vygotski (1988). As salas de aulas articuladas poderiam ser disseminadas na estrutura arquitetônica escolar nas diversas salas já existentes; já os espaços de colaboração exigiriam maiores adaptações e mais recursos, principalmente tecnológicos. São propostas com dimensões e exigências estruturais distintas, mas que convergem para o mesmo fim: a maior valorização do espaço físico para o ensino, sobretudo o de Ciências.

\section{CONSIDERAÇÕes Finais}

Visto que atualmente o ensino de ciências - em especial o de física - apresenta um distanciamento entre o conteúdo e o cotidiano do aluno, bem como entre o conteúdo e as ferramentas em TDIC, é necessário propor um ambiente pensado na vinculação dessas perspectivas. Pensando nisso, este ensaio trouxe à luz contribuições teóricas.

A primeira veio da discussão da geometria e da configuração arquitetônica dos componentes das salas de aprendizagem. Notou-se que esse aspecto deve ser mais estudado, pois, como apontou Foucault (1999a; 1999b; 1999c), "em torno de cada uma dessas 'representações' morais, os escolares se comprimirão com seus professores e os adultos aprenderão que lição ensinar aos filhos". Esse foi o primeiro achado explorado neste ensaio: a arquitetura dos espaços escolares influencia na construção dos comportamentos e na (re)produção as práticas escolares (MANZUR, 2015; CARVALHO; FABIARZ, 2014; KÜNZLE, 2007, dentre outros).

A segunda exploração teórica desta investigação examinou que Vygotski (1988) e Lévy (1993), cada um seu modo, demonstraram a importância de se considerar o processo 
social. Lévy (1993) apreendeu esse processamento a partir das tecnologias e suas interações na cibercultura. Vygotski (1988) notou a relevância do social no desempenho cognitivo a partir da noção de zona de desenvolvimento proximal. Desses autores, despontou o segundo entendimento deste ensaio: as TDIC podem ser integradas ao processo de ensino e aprendizagem como instrumentos simbólicos (VYGOTSKI, 1988) e que esse acolhimento pode se dar a partir de links e hiperlinks (LÉVY, 1993) presentes no espaço escolar.

A terceira contribuição deste estudo decorreu da reflexão sobre a arquitetura no processo de aprendizagem. A partir dos aportes de Bernardes (2018), sustentados pela perspectiva da Teoria da Restauração da Atenção, argumentou-se que os aspectos do ambiente físico podem propiciar a maior recuperação da capacidade humana de atenção dirigida (KAPLAN; KAPLAN, 1989; KAPLAN, 1995). Para isso, foi retomado, de maneira resumida, o conceito de ambiente restaurador (KAPLAN, 1995), o qual adotou-se em oposição ao panóptico foucaultiano - embora essa oposição não seja assumida pelos propositores de nenhuma das duas teorias - para se entender o espaço escolar. Esse conceito foi reforçado pela reflexão de Frago e Escolano (2001) que observaram que os espaços e os tempos auxiliam a constituir memórias e estas nos habitam. Com isso, chegou-se ao terceiro achado: na contramão do efeito panóptico e do tempo disciplinar (FOUCAULT, 1999a), pode-se apreender um ambiente restaurador (BERNARDES, 2018; KAPLAN, 1995) que permite os links e os hiperlinks (LÉVY, 1993) que incentivam a aprendizagem significativa (AUSUBEL, 1968).

A quarta contribuição foi a proposição de dois modelos arquitetônicos para o ensino de Ciências - mas que, ressalve-se, esses modelos podem ser aplicados em outras disciplinas. $\mathrm{O}$ primeiro modelo é o de sala de aula articulada, que está apoiado nos conceitos de flexibilidade e mobilidade, os quais são implementados a partir de mesas modulares. A sugestão foi de mesas em formato de trapezoide (cf. Figura 1). O segundo modelo é o espaço de colaboração, o qual foi inspirado no modelo de coworking. A indicação é que esse espaço seja construído de maneira circular, com projetor e mesas modulares (cf. Figura 2). Os dois modelos são teóricos e foram baseados nas propostas de Sanoff et al. (2001).

Essas quatro contribuições possuem suas limitações. A principal delas é que os dois modelos apresentados não foram implementados em espaços físicos de unidades escolares, carecendo, portanto, de estudos empíricos. As propostas deste estudo são ainda explorações teóricas que estão balizadas em estudos recentes de especialistas de diversas áreas. É uma abordagem interdisciplinar e, como tal, respeita as distintas epistemologias que sustentam cada um dos campos postos em diálogo, todavia, pode haver pontos de divergências entre os pontos de vista dos estudiosos e suas respectivas áreas de estudo. Essas são algumas das observações que justificam a classificação deste estudo como um ensaio, uma vez que, como define Adorno (1994, p. 180), "é inerente à forma do ensaio a sua própria relativização: ele precisa compor-se de tal modo como se, a todo momento, pudesse interromper-se. Ele pensa aos solavancos e aos pedaços, assim como a realidade é descontínua, encontra sua unidade através de rupturas e não à medida que as escamoteia".

Como se pode depreender, este estudo traz as possibilidades que o cenário contemporâneo globalizado proporciona. A unidade escolar é um microcosmos e pode ser explorado. Para tanto, a disciplina de Ciências não pode mais se encalacrar nos moldes tradicionais, sobretudo na apropriação do espaço físico para a promoção do processo de ensino-aprendizagem. A contribuição deste ensaio é trazer propostas que se alinham às 
juventudes da Geração $Y$, as quais abrem outras dimensões para se enfrentar o protagonismo do educador e promover, assim, a aprendizagem crítica e significativa do alunado.

Por conseguinte, do mesmo modo que Vygotski (1988, p. 56) defendeu que "o aprendizado das crianças começa muito antes delas frequentarem a escola", este ensaio sustentou, em suas entrelinhas, que o aprendizado dos estudantes depende também das estruturas arquitetônicas e tecnológicas de nossas escolas.

\section{REFERÊNCIAS}

ALVES FILHO P. J. Atividades Experimentais: do Método à Prática Construtivista. 302 f. Tese (Doutorado em Educação: Ensino de Ciências Naturais) - Universidade Federal de Santa Catarina, 2000.

BRASIL. Ministério da Educação. Lei de Diretrizes e bases da educação (n.939496). Brasília, DF, 1996. Disponível em < http://portal.mec.gov.br/arquivos/pdf/ldb.pdf>. Acesso em julho de 2017.

CAMARGO, E. P. O Ensino de Física no Contexto da Deficiência Visual: elaboração e Condução de Atividades de Ensino de Física para Alunos Cegos e com Baixa Visão. 272 f. Tese (Doutorado em Educação para a Ciência) - Faculdade de Educação, Universidade Estadual de Campinas, 2005.

CARNEIRO, Eudocha et al. EXPERIMENTO ADAPTADO PARA ESTUDANTES COM DEFICIÊNCIA VISUAL: ESTUDO DA RELAÇÃO SOLUBILIDADE VERSUS TEMPERATURA/Experiment adapted for visually disabled students: study of relation between solubility and temperature. Revista Aretél Revista Amazônica de Ensino de Ciências, v. 9, n. 18, p. 173-181, 2017.

CAT-Comitê, De Ajudas Técnicas. Ata da Reunião VII, de dezembro de 2007 do Comitê de Ajudas Técnicas. Secretaria Especial dos Direitos Humanos da Presidência da República (CORDE/SEDH/PR), 2007.

COLL, C. et. al. Os conteúdos na reforma: ensino e aprendizagem de conceitos, procedimentos e atitudes. Porto Alegre: Artes Médicas, 1998.

DE SOUZA, Flaviane; PALMA, Francisco. PROPOSTA DE UM SISTEMA DE REPRESENTAÇÃO DA REFLEXÃO DA LUZ EM UM ESPELHO ESFÉRICO PARA ALUNOS COM DEFICIÊNCIA VISUAL/A proposal of a representation of light reflection in spherical mirrors for teaching students with visual impairment. Revista Aretél Revista Amazônica de Ensino de Ciências, v. 9, n. 20, p. 67-71, 2017.

DRIVER, R. Psicologia cognitiva y esquemas conceptuales de los alumnos. Enseñanza de lãs Ciências, v.4, n.1, p.3-15, 1986. 
EVANGELISTA, F. L. O ensino de corrente elétrica a alunos com deficiência visual. 2008.

EVANGELISTA, F. L. Física para pessoas com deficiência visual: ensino de corrente elétrica. 1 ed. Concórdia: Jucimar Peruzzo, 2019. v. 1. 134p.

FACCIO, Miguel et al. Força e movimento: concepções alternativas no Ensino Superior. Revista Educar Mais, v. 3, n. 2, p. 173-191, 2019.

FREITAS, Wesley Ricardo de Souza; JABBOUR, Charbel José Chiappetta. O Estudo de Caso(s) como Estratégia de Pesquisa Qualitativa: fundamentos, roteiros de aplicação e pressupostos de excelência. www. abepro. com. br. Acesso em, v. 12, p. 12, 2016.

GALVÃO FILHO, Teófilo Alves. Tecnologia assistiva para uma escola inclusiva: apropriação, demanda e perspectivas. 2009.

GRECA, I. M.; MOREIRA, M. A. Além da detecção de modelos mentais dos estudantes: uma proposta representacional integradora. Investigações em Ensino de Ciências, v. 7, n.1, 2002. Disponível em <http://www.if.ufrgs.br/public/ensino/revista.htm>. Acesso em julho de 2017.

GRUPO DE REELABORAÇÃO DO ENSINO DE FÍSICA. Eletromagnetismo. São Paulo: Edusp, 1991. Disponível em < http:/ / fisica.cdcc.sc.usp.br/GREF/livros.html>. Acesso em julho de 2017.

LIMA, Maria da Conceição Barbosa; DE CASTRO CATARINO, Giselle Faur. Formação inicial de professores de Física: a questão da inclusão de alunos com deficiências visuais no ensino regular. Ciência E Educação, v. 18, n. 1, p. 81-98, 2012.

MASINI, E. F. S. Impasses sobre o Conhecer e o Ver. In: O perceber e o relacionar-se do deficiente visual: orientando professores especializados. Brasília: CORDE, 1994.

OLIVEIRA, Dirlene Aparecida de. Concepções espontâneas sobre o conceito de movimento entre estudantes de física (mecânica) da UFFS-Campus Laranjeiras do Sul. 2018.

PIETROCOLA, M. Construção e realidade: o papel do conhecimento físico no entendimento do mundo In: PIETROCOLA, M. (Orgs). Ensino de Física: conteúdo, metodologia e epistemologia numa concepção integradora. Florianópolis: Editora da UFSC, 2001.

PIMENTEL, Andréia Guerra; ARAGON, Glauca Torres. JOGO EDUCACIONAL E MEIO AMBIENTE: ADAPTAÇÃO DE UM LIVRO-JOGO PARA ALUNOS COM DEFICIÊNCIA VISUAL. Revista Aretél Revista Amazônica de Ensino de Ciências, v. 11, n. 24, p. 156-165, 2019.

SANTOS, Pâmela Mello dos et al. Evolução biológica na perspectiva de estudantes do ensino médio: das concepções espontâneas aos saberes escolares. 2017. 
SIPEC, I. Um diálogo sobre as concepções alternativas presentes no ensino das ciências. Arquivos do Museu Dinâmico Interdisciplinar, v. 21, n. 3, p. 90-101, 2017.

SOLIS VILLA, R. Ideas intuitivas y aprendizage de las ciencias. Enseñanza de las Ciencias, v.2, n.2, p.1-19, 1994.

SOUZA, O. S. Nas entrelinhas da inclusão escolar de alunos com necessidades educativas especiais: o desafio da formação docente. 194 f. Tese (Doutorado em Educação) Faculdade de Educação, Universidade Federal do Rio Grande do Sul, 2002.

VIENNOT, L. Spontaneous reasoning in elementary dynamics. European Journal of Science Education, v.1, n.2, p.205-221, 1979.

VYGOTSKI, L.S. Obras escogidas. Madrid: Editora Pedagógica, 1998.

ADORNO, Theodor. O ensaio como forma. In: COHN, Gabriel (Org.). Theodor W. Adorno Sociologia. São Paulo: Ática, 1994, p. 167-187.

ALVES, Fernanda Sales. Iluminação universal: ergonomia e design universal aplicados ao projeto lumínico em sala de aula. 116 f. 2014. Dissertação (Mestrado em Artes Visuais) Universidade Federal da Bahia, 2014.

ARRAIS NETO, Enéas de Araújo; RICCA, Diego Enéas Peres; SOUZA, Raphael Pires de. Arquitetura escolar: currículo ou curral? Revista LABOR, Fortaleza, v. 1, n. 16, p. 137-151, 2016.

AUSUBEL, David Paul. Educational psychology: a cognitive view. Nova York: Holt, Rinehart and Winston, 1968.

BERGMANN, Jonathan; SANS, Aaron. Sala de aula invertida: uma metodologia de aprendizagem. Tradução de Afonso Celso da Cunha Serra. Rio de Janeiro: LTC, 2018.

BERNARDES, Marina. Configuração arquitetônica de salas de aula como ambientes promotores do bem-estar. 188 f. 2018. Dissertação (mestrado) - Universidade Federal de Santa Catarina, Centro Tecnológico, Programa de Pós-Graduação em Arquitetura e Urbanismo, Florianópolis, 2018.

BORGES, Antonio Tarcísio. O papel do laboratório no ensino de ciências. Belo Horizonte: Colégio Técnico da UFMG, 1996.

CARVAlHO, Anna Maria Pessoa de. Prefácio. CACHAPUZ, António et al. (Orgs.). A necessária renovação do ensino das Ciências. São Paulo: Cortez, 2005, p. 9-13. 
CARVALHO, Ricardo Artur; FABIARZ Jackeline Lima. A disciplina na sala de aula: arquitetura e design como afirmação de concepções de ensino e aprendizagem. Arcos Design. Rio de Janeiro, v. 8, n. 1, p. 96-113, jun. 2014.

FOUCAULT, Michel. Vigiar e punir: nascimento da prisão. Tradução de Raquel Ramalhete. 20. ed. Petrópolis: Vozes, 1999a.

FOUCAULT, Michel. Em defesa da sociedade: curso no College de France (1975-1976). São Paulo: Martins Fontes, 1999b.

FOUCAULT, Michel. A verdade e as formas jurídicas. Tradução de Roberto Cabral de Melo Machado e Eduardo Jardim Morais. Rio de Janeiro: NAU, 1999c.

FOUREZ, Gérard. Crise no ensino de Ciências? Tradução de Carmem Cecília de Oliveira. Investigações em Ensino de Ciências. Porto Alegre, v. 8, n. 2, p. 109-123, 2003.

FONTANA, Roseli; CRUZ, Maria Nazaré da. Psicologia e trabalho pedagógico. São Paulo: Atual, 1997.

FRAGO, Antonio Viñao; ESCOLANO Augustin. Currículo, espaço e subjetividade: A arquitetura como programa. 2. ed. Rio de Janeiro: DP\&A, 2001.

FREIRE, Paulo. Pedagogia do Oprimido. São Paulo: Paz e Terra, 1996.

GARDNER, Howard. Inteligências múltiplas: a teoria na prática. Tradução de Maria Adriana Veríssimo Veronese. Porto Alegre: Artes Médicas, 1995.

GRESSLER, Sandra Christina; GÜNTHER, Isolda de Araújo. Ambientes restauradores: definição, histórico, abordagens e pesquisas. Estudos de Psicologia, Brasília, v. 18, n. 3, p. 487-495, jul-set.2013.

JUNG, Carl Gustav et al. O homem e seus símbolos. Tradução de Maria Lúcia Pinho. 3. ed. Rio de Janeiro: Harper Collins, 2016.

KAPLAN, Rachel; KAPLAN, Stephen. The experience of nature: a psychological perspective. Nova Iorque: Cambridge University, 1989.

KAPLAN, Stephen. The restorative benefits of nature: Toward an integrative framework. Journal of Environmental Psychology, v. 1, n. 3, p. 169-182, 1995.

KAPLAN, Rachel; KAPLAN, Stephen; RYAN, Robert. With people in mind: Design and management of everyday nature. Washington: Island Press, 1998.

KOWALTOWSKI, Doris. Arquitetura escolar: o projeto do ambiente de ensino. São Paulo: 
Oficina de Textos, 2011.

KÜNZLE, Maria Rosa Chaves. Os espaços escolares e a constituição de um programa antidisciplinar. Roteiro, Joaçaba, v. 32, n. 2, p. 221-244, jul.-dez. 2007.

LÉVY, Pierre. As tecnologias da inteligência - O futuro do pensamento na era da informática. Tradução de Carlos Irineu da Costa. São Paulo: Editora 34, 1993.

MACHADO, Roberto. Foucault, a ciência e o saber. 3 ed. Rio de Janeiro: Jorge Zahar, 2006.

MAZUR, Eric. Peer instruction: a revolução da aprendizagem ativa. Tradução de Anatólio Laschuk. Porto Alegre: Penso, 2015.

MEDINA, Paloma Fraga; KRAWULSKI, Edite. coworking como modalidade e espaço de trabalho: uma análise bibliométrica. Cadernos de psicologia social do trabalho, São Paulo, v. 18, n. 2, p. 181-190, 2015.

MOREIRA, M. A. Pesquisa básica em educação em ciências: uma visão pessoal. In: I Congresso Iber-Americano de Educação em Ciências Experimentais - CIAECE, Anais do I CIAECE, La Serena, Chile, 1998.

MOREIRA, M. A. Uma análise crítica do ensino de Física. Estudos Avançados. São Paulo, v. 32, n. 94, p. 73-80, 2018.

MÜLLER, Maykon Gonçalves; ARAUJO, Ives Solano; VEIT, Eliane Angela. Inovação na prática docente: um estudo de caso sobre a adoção de métodos ativos no ensino de Física universitária. Revista Electrónica de Enseñanza de las Ciencias. Pontevedra, v. 17, n. 1, p. 44-67, 2018. Disponível em: http://reec.uvigo.es/volumenes/volumen17/REEC_17_1_3_ex1094.pdf Acessado em: 20 mai. 2020.

NOVAK, Gregor et. al. Just-in-time teaching: blending active learning with web technology. Upper Saddle River: Prentice Hall, 1999.

OLIVEIRA, Marta Kohl. Aprendizado e desenvolvimento: um processo histórico. São Paulo: Scipione, 1997.

PALFREY, John; GASSER, Urs. Born digital: understanding the first generation of digital natives. New York, Basic book, 2008.

ROCHA-DE-OLIVEIRA, Sidinei; PICCININI, Valmiria Carolina; BITENCOURT, Betina Magalhães. Juventudes, gerações e trabalho: é possível falar em Geração Y no Brasil? Organizações e Sociedade. Salvador, v.19, n. 6, p. 551-558, jul.-set., 2012.

ROSA, Cleuci Werner; ROSA, Álvaro Becker Ensino de Física: objetivos e imposições no Ensino 
Médio. Revista Electrónica de Enseñanza de lãs Ciencias. Pontevedra, v. 4, n. 1, p. 1-18, 2005. Disponível em: http://reec.webs.uvigo.es/volumenes/volumen4/ART2_Vol4_N1.pdf Acessado em: 20 mai. 2020.

SANTOS, Gustavo Henrique dos; ALVES, Lynn; MORET, Marcelo A. Modellus: Animações interativas mediando à aprendizagem significativa dos conceitos de Física no Ensino Médio. Revista Científica da Escola de Administração do Exército. v. 2, p. 88-108, 2006.

SANOFF, Henry et al. School building assessment methods. National Clearinghouse for Educational Facilities, p. 1-43, 2001.

SEVERIAN, Maria Rosa. Vigilância e poder na sala de aula: as influências do panóptico no ambiente de ensino de língua estrangeira. Revista EntreLínguas. Araraquara, v.3, n.1, p. 75-94, jan./jun. 2017.

SOUZA, Telmo Machado de. O uso de tablets na educação: "maravilhamento", "embasbacamento", possibilidade de contribuição na aprendizagem. 2015 88f. Dissertação (Mestrado em Educação) - Faculdade de Educação, Universidade Federal do Rio Grande do Sul, Porto Alegre, 2015.

SFORNI, Marta Sueli de Faria; GALUCH, Maria Terezinha Bellanda. Apropriação de instrumentos simbólicos: implicações para o desenvolvimento humano. Educação, Porto Alegre, v. 32, n. 1, p. 79-83, jan./abr. 2009.

SIEMENS, George. Connectivism: A Learning Theory for the Digital Age. International Journal of Instructional Technology \& Distance Learning, v.2, p. 3-10, 2005.

SUNAGA, Alexandre; CARVALHO, Camila de. As tecnologias digitais no Ensino Híbrido. In: BACICH, Lilian; NETO, Adolfo Tanzi; TREVISANI, Fernando de Mello. (Orgs.) Ensino Híbrido: personalização e tecnologia na educação. Porto Alegre: Penso, 2015, p. 67-80.

TABILE Ariete Fröhlich; JACOMETO, Marisa Claudia Durante. Fatores influenciadores no processo de aprendizagem: um estudo de caso. Revista Psicopedagogia - Revista da Associação Brasileira de Psicopedagogia, São Paulo, v. 3, n. 103, p. 75-86, 2017.

VALENTE, José Armando. Blended learning e as mudanças no ensino superior: a proposta da sala de aula invertida. Educar em Revista, Curitiba, Brasil, Edição Especial n. 4, p. 79-97, 2014.

VIEIRA, Valéria. A aprendizagem: um grande desafio para o ensino de ciências. Revista Ciências \& Ideias, Rio de Janeiro, v. 10, n. 1, p. i-v, jan.-abr., 2019.

VYGOTSKI, Lev. A formação social da mente: o desenvolvimento dos processos psicológicos superiores. Tradução de José Cipolla Neto, Luis Silveira Menna Barreto e Solange Castro 
Afeche2 ed. São Paulo: Martins Fontes, 1988.

XAVIER, Antonio Carlos. Letramento digital: impactos das tecnologias na aprendizagem da Geração Y. Calidoscópio. São Leopoldo, v. 9, n. 1, p. 3-14, 2011. 